\title{
Droplet Measurement below Single-Layer Grid Fill
}

\author{
Pavol Vitkovic ${ }^{1, \text { a }}$ \\ ${ }^{1}$ CTU in Prague, Department of Fluid Dynamics and Thermodynamics, 16607 Prague, Czech Republic
}

\begin{abstract}
The main part of the heat transfer in a cooling tower is in a fill zone. This one is consist of a cooling fill. For the cooling tower is used a film fill or grid fill or splash fill in the generally. The grid fill has lower heat transfer performance like film fill usually. But their advantage is high resistance to blockage of the fill. The grid fill is consisted with independent layers made from plastic usually. The layers consist of several bars connected to the different shapes. For experiment was used the rhombus shape. The drops diameter was measured above and below the Grid fill.
\end{abstract}

\section{Introduction}

The wet cooling towers [1] are used wherever need transfer the low potential heat to the atmosphere through the cooling water by the air. It is basically a mixed heat exchanger [2]. The wet cooling tower are consist of a shell [1], a water distribution system with a nozzles [3], a fills [4], [5] and a drift eliminators [6]. The nozzle creates a spray zone [3], [7] and the fill create rain zone [8]. These are two important zones in this experimental study of the Grid fill. The spray zone is above the fill and the rain zone is below the fill. The purpose of this paper is to measure the droplets size at the entry to the Grid fill and the droplet size generated by the Grid fill with the rhombus shape bar.

\section{Measurement method}

The Laser-Induced Fluorescence (LIF) method is used for obtaining an experimental data. LIF has excellent detection sensitivity because a signal is observed against a dark background [9]. Fluorescent dyes (Rhodamine B) in water can absorb light (green light) at one frequency and subsequently reemit light at a different frequency. Because the fluoresced light is of a different frequency than the excitation light can be filtered out. The laser beam is expanded into a sheet using two cylindrical lenses. The cylindrical lens produces a light sheet of few millimeter thick. Rhodamine B as a tracer dye after absorbing light with the wavelength of $532 \mathrm{~nm}$ emitted light of wavelength between 500 and $700 \mathrm{~nm}$. Excitation light was filtered by a red filter with the cut-on wavelength about $600 \mathrm{~nm}$. The red filter was installed at the lens of a camera.

\section{Experimental setup}

The test facility has a modular construction. It is consist of a two sections made from a plexiglass. A cross-section is $300 \times 288 \mathrm{~mm}$. The total height of the test facility is $900 \mathrm{~mm}$. The first section is consist of a collecting basin with a pump. The pump has maximum flow rate $0.01083 \mathrm{~m}^{3} \mathrm{~s}^{-1}$. The water flowrate of the pump is controlled by a voltage. At a bottom of the basin is placed a piece of drift eliminator. Because it blocks secondary water droplets from a drop impact on the water surface. The second section has a water distribution system.

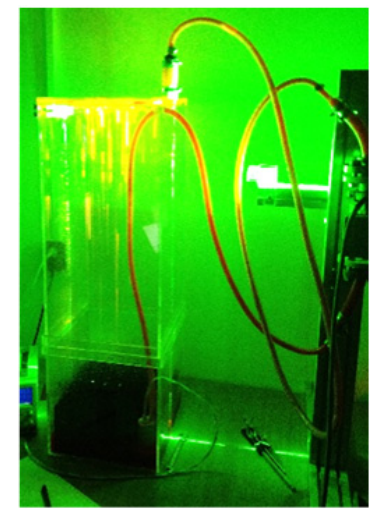

Figure 1. Test facility - experiment setup

A droplets generator was made from a plexiglass sheets. It's consist of a three layers of a plexiglass cut by a laser. The last layer has holes with $1 \mathrm{~mm}$ diameter arranged to the net. The middle layer has a rectangular distribution channels. And the third layer has a connection tube for pipelines. All the layers are glued together into the one piece.

\footnotetext{
${ }^{\mathrm{a}}$ Corresponding author: pavol.vitkovic@fs.cvut.cz
} 


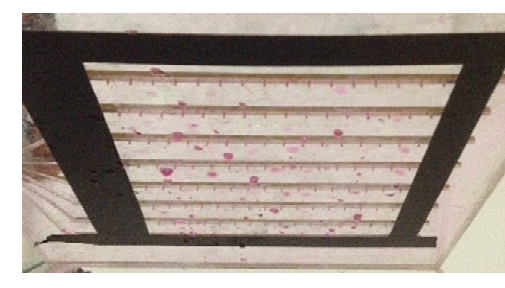

Figure 2. Droplets generator

We can expect about $3.5 \mathrm{~mm}$ diameter water drops. For predicted calculation was used equation (1) of an approximate static drops formation [10]:

$$
D=\left(\frac{6 \cdot d_{o} \cdot \sigma}{\rho_{L} \cdot g}\right)^{\frac{1}{3}}
$$

The measurement of the spray zone [7] shows that $60 \%$ of the total drops has the size larger than $3.5 \mathrm{~mm}$ and the largest drops are $7.8 \mathrm{~mm}$. And the corresponding Sauter mean diameter is $3.25 \mathrm{~mm}$.

The Sauter mean drop diameter is defined as

$$
d_{32}=\frac{\sum_{i=1}^{m} n_{i} d_{i}^{3}}{\sum_{i=1}^{m} n_{i} d_{i}^{2}}
$$

For measurement was used the full range pump operate (from $5 \mathrm{~V}$ to $12 \mathrm{~V}$ with $1 \mathrm{~V}$ step). Below $5 \mathrm{~V}$ the pump can't pull the water to the droplets generator.

Table 1. Measurement points setup

\begin{tabular}{|c|c|}
\hline Voltage (V) & Water flowrate $\left(\mathbf{m}^{\mathbf{3}} \mathbf{~ s}^{-\mathbf{1}}\right)$ \\
\hline 5 & 0.00176 \\
\hline 6 & 0.00327 \\
\hline 7 & 0.00422 \\
\hline 8 & 0.00493 \\
\hline 9 & 0.00569 \\
\hline 10 & 0.00627 \\
\hline 11 & 0.00696 \\
\hline 12 & 0.00747 \\
\hline
\end{tabular}

The drop size distribution based on the volume of the droplets generator is at Figure. 3. All measurement point has similar drop size distribution (triangle mark) except point with lowest water flow rate $\left(0.00176 \mathrm{~m}^{3} \mathrm{~s}^{-1}-\mathrm{star}\right.$ mark) and the second lowest $\left(0.00327 \mathrm{~m}^{3} \mathrm{~s}^{-1}-\right.$ circle mark). The mean drop size is lower as expected from formula (1).

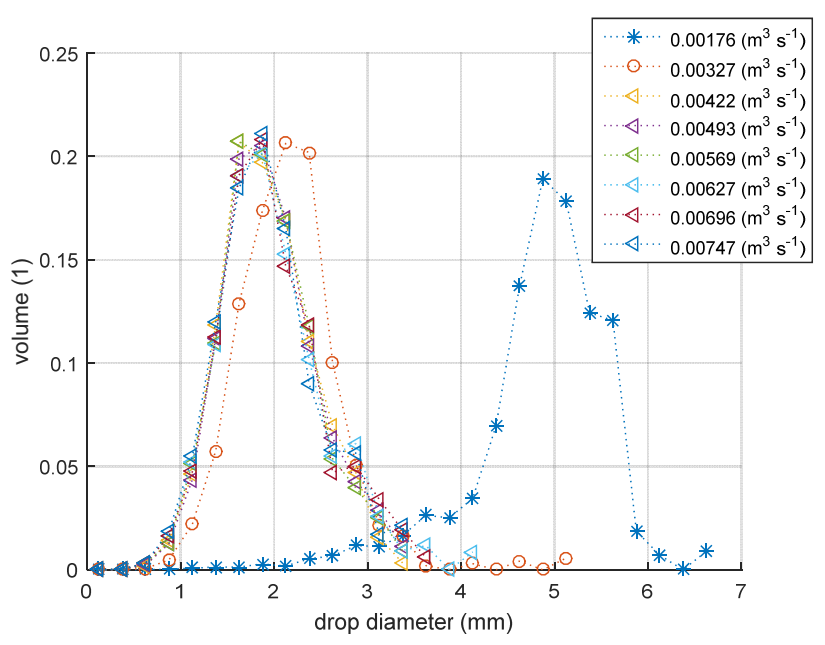

Figure 3. Droplet generator drop size distribution based on volume.

The experimental equipment consists of the GigE Sony camera XCG-H280E and the continual laser $1000 \mathrm{~mW}$ with the wavelength of $532 \mathrm{~nm}$ (green light) for the sheet generation. The exposition time of the camera is possible to be set up between $0.0002 \mathrm{~s}$ and $2 \mathrm{~s}$. The experiment was conducted at exposition time $0.0005 \mathrm{~s}$.

For experiment, it was used the Grid fill with the rhombus shape bar (Figure 4). The side length of the rhombus is $53 \mathrm{~mm}$ and the thickness of the bar is $5 \mathrm{~mm}$.

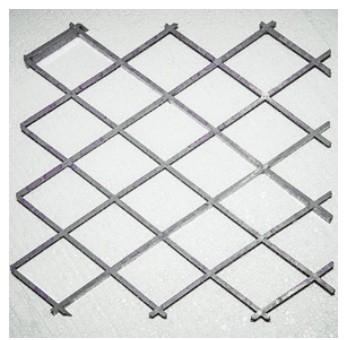

Figure 4. Grid fill with rhombus shape bar.

\section{Experimental Results}

Before measuring it was necessary to a calibrated measurement. For this purpose, graph paper was chosen as a calibration target. After calibration, it was possible to calculate droplets diameter in millimetre size. The signal from the fluorescent light is converted to white blobs on a black background. From the drop, area is calculated an equivalent spherical drop diameter. The drop size distribution based on volume are at following figures.

For all measurements points the Sauter mean drop diameter was computed. The Sauter mean drop diameter is calculated from (2).

Figure 6. provides the Sauter mean drop diameter for all measured points. The Grid fill generates the Sauter mean drop diameter about $d_{32}=7.5 \mathrm{~mm}$ except the point with lowest water flow rate $\left(d_{32}=11.5 \mathrm{~mm}\right)$. 

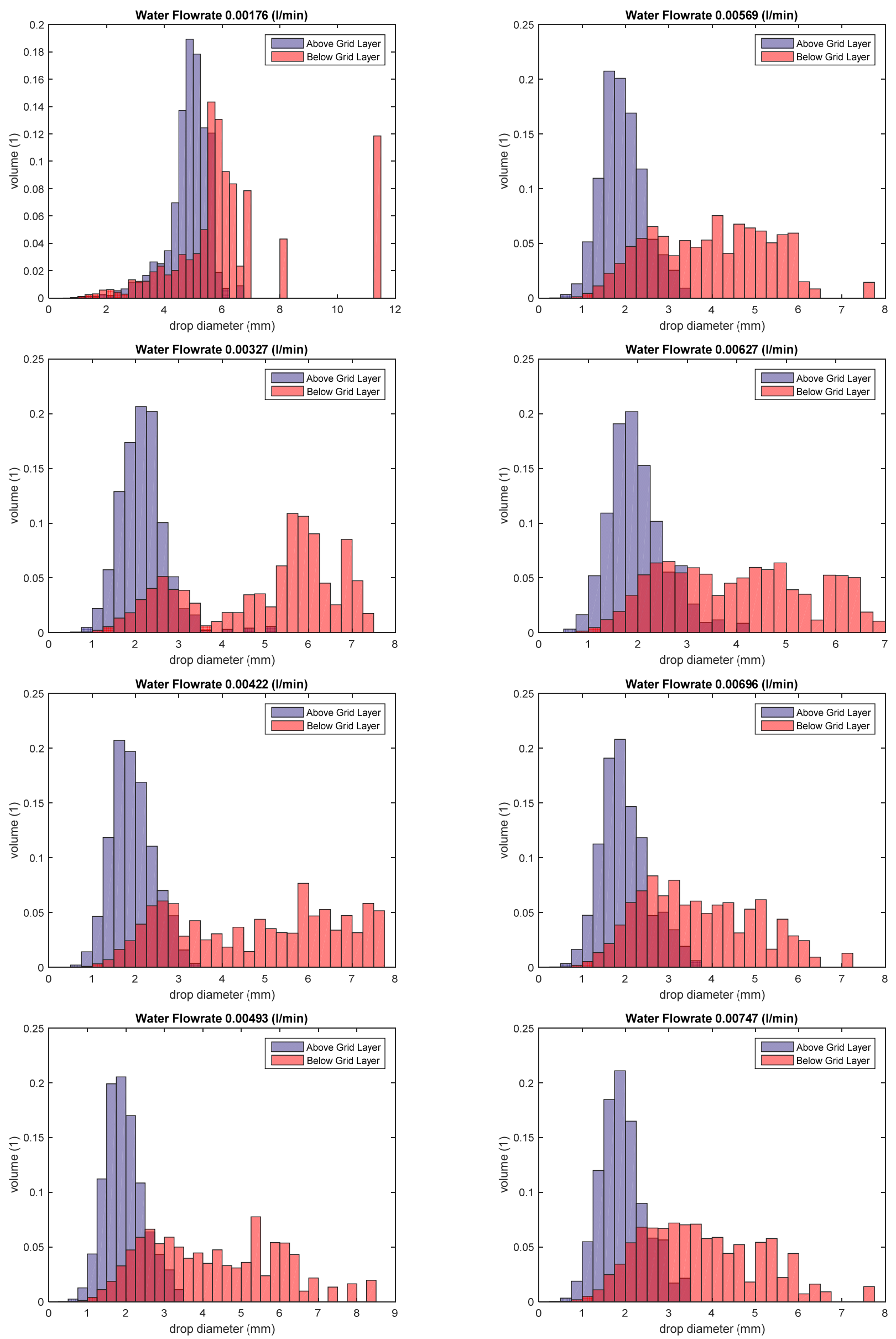

Figure 5. Drop size histogram based on volume. 


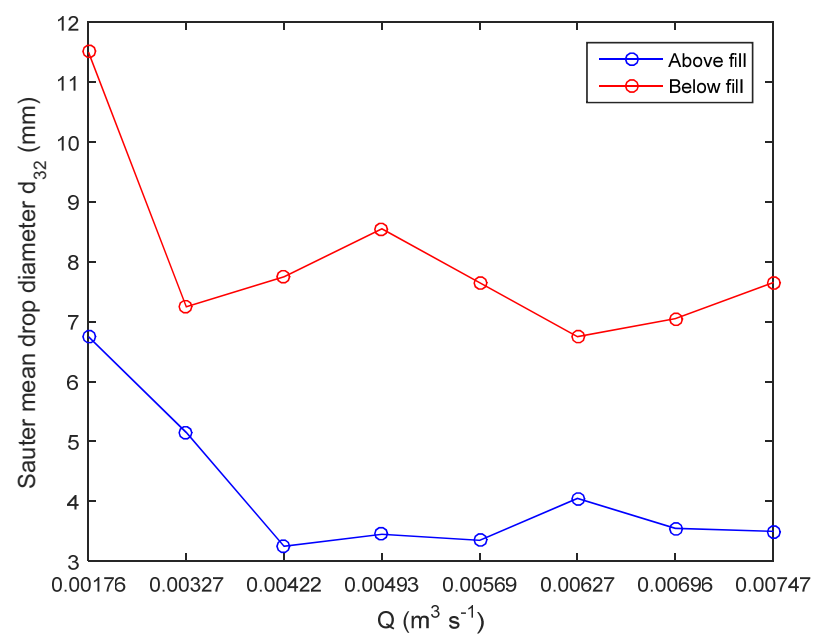

Figure 6. Sauter mean drop diameter for a different water flow rate.

\section{Conclusion}

The drop size distribution below and above the Grid fill with rhombus shaped bar was obtained. What is interesting in this data is generating bigger droplets by the Grid fill as droplets before coming to the Grid fill. The areas from where large drops drip is a bar intersection [4].

The section between the two layers of Grid fill is the rain zone basically. It can be described by the mathematical model of the rain zone [11], [12]. The results of this study show that we can obtain the size of droplets between the Grid fill as the boundary conditions for the mathematical model of the rain zone [11]. This is an important issue for future research. In the future investigation, it might be possible to use a different drops size at the entry of the Grid fill.

\section{Acknowledgments}

The author acknowledges the support received from Advanced technologies for heat and electricity production TE01020036 and Centre for research of multiphase flow and thermodynamics processes in renewable sources and energetics - NEW ENERGY supported by the European Union (CZ.2.16/3.1.00/22130).

\section{References}

1. D.G. Kröger, Air-Cooled Heat Exchangers and Cooling Tower, (2004)

2. VDI Heat Atlas, (2010)

3. P. Vitkovic, EPJ Web of Conferences, 92, 02109, (2015)

4. R. Terblanche, H.C.R. Reuter, D.G. Kröger, Applied Thermal Engineering, 29, 1552-1560, (2009)

5. L. Dvorák, J. Nožička, EPJ Web of Conferences, 67, 02024, (2014)

6. J. Stodůlka, R. Vitkovicova, EPJ Web of Conferences, 92, 02086, (2015)
7. Reuter, H.C.R., Viljoen, D.J., Kröger, D.G., IHTC 14, 4, pp. 619-628 (2010).

8. L. Dvořák, J. Čížek, J. Nožička, EPJ Web of Conferences, 92, 02014, (2015)

9. R. N. Zare, Annual Review of Analytical Chemistry, 5, 1-14, (2012)

10. A. H. Lefebvre, Atomization and sprays, (1989)

11. T. Hyhlík, Engineering Mechanics, 21, 240-243, (2014)

12. T. Hyhlík, ICCT 2014 International Conference, 219-226, (2014) 